\title{
Adapting to the Euro: Strategies of Conversion between-currency
}

Eleonora Strazzari, Raffaella Nori, Luca Bensi and Fiorella Giusberti

\section{OpenEdition}

\section{Journals}

Electronic version

URL: http://journals.openedition.org/cpl/438

DOI: $10.4000 / \mathrm{cpl} .438$

ISSN: $1379-6100$

Publisher

Centre PsyCLÉ

Electronic reference

Eleonora Strazzari, Raffaella Nori, Luca Bensi and Fiorella Giusberti, « Adapting to the Euro: Strategies of Conversion between-currency ", Current psychology letters [Online], 15, Vol. 1, 2005 | 2005, Online since 30 March 2006, connection on 08 September 2020. URL : http://journals.openedition.org/cpl/ 438 ; DOI : https://doi.org/10.4000/cpl.438

This text was automatically generated on 8 September 2020

(c) All rights reserved 


\title{
Adapting to the Euro: Strategies of Conversion between-currency
}

\author{
Eleonora Strazzari, Raffaella Nori, Luca Bensi and Fiorella Giusberti
}

Received October 28, 2004

Revised January 10, 2005

Accepted January 11, 2005

Introduction

The introduction of the new European currency has been an extraordinary and innovative event, which has produced significant changes, not only in the global economy and markets, but also in some other important fields, like psychological and social ones.

During these last years, a number of studies have examined the problems linked to this transition either from a psychosocial (e.g. Raimondi, 1998; Kokkinaki, 1998; Legrenzi, 1998; Meier \& Kirchler, 1998; Müller-Peters, 1998; Pepermans \& Verleye, 1998; Routh \& Burgoyne, 1998; van Everdingen \& van Raaij, 1998; Legrenzi \& Salmaso, 1999), or numerical cognition point of view (Lemaire \& Lecacheur, 2001; Lemaire, Lecacheur \& Barbey, 2001; Dehaene \& Marques, 2002; Gamble, Gärling, Charlton \& Ranyard, 2002; Mussweiler \& Englich, 2003).

Studying this area can tell us a lot about the changes in our everyday life that have produced uncertainty, vulnerability to biasing influences and adaptation of habits that the average European Union citizen has had to undergo.

One of the first relevant modifications that we have had to make has been in the language. Adopting the Euro has meant adopting new labels like "Euro" and "Cent" which have replaced our previous monetary labels and which have brought significant changes to the lexicosyntactic structure of terms regarding money (Marques, 1999).

One of the most difficult tasks for citizens of the various states (mostly at the beginning, when the old and the new currencies were used together, but even now, after 2 years of using the Euro) is to understand how much a product or a service costs 
(Marques, 1999). Our cognitive system, in fact, uses a "prices memory" to automatically judge if a product is well-priced or not. This memory was generated for the old currency, over the years, and suddenly had to change and be replaced by a new one. At least at the beginning, the absence of this memory generated uncertainty as to the goods' quality/cost ratio (Bini Smaghi, 2001).

In fact, recent research by Dehaene and Marques (2002) showed that this uncertainty was generated by the absence of any "mental map" for the new currency. According to these authors, there is a price expertise to be acquired for any single currency: each encounter with a product and its price leads to the creation of an association between the mental representation of the product and the corresponding number, represented as activation at the appropriate location on the number line distribution.

There is something else that had to change: the "psychological price thresholds", like 10,000 Lira in Italy; we should adopt new Euro thresholds, which do not necessarily have the same psychological and economic value of those in the old currency (Legrenzi, 2001). For example: can we think "it is cheap, it costs just 5 euro!" in the same way that we thought "it is cheap, it costs just 10,000 Lira!", or is it not easier to think "it is cheap, it costs just 10 euro!"?

As the Italian conversion rate is $€ 1=\operatorname{ITL} 1,936.27$, the rounded figure $€ 1=\operatorname{ITL} 2,000$ seems to be the most simple method of converting and so the quantitative difference between prices is reduced to a scale of $1: 2,000$. This can modify the perception of price difference between products if consumers do not adjust to the fact that a smaller quantitative increase in Euro means a larger increase in spending than with their previous currency (Marques, 1999). An explanation can come from a recent study on the money illusion in the case of the Euro (Gamble, Gärling, Charlton \& Ranyard, 2002). The authors showed that people have the tendency to disregard the real worth of money and instead focus on the nominal value, that is, the numbers printed on notes and coins. With the introduction of the Euro, people are susceptible to this bias when converting their former national currency into Euro, and the nominal value of the Euro is either smaller or larger depending on the exchange rate of the national currency. In the Italian case, smaller by half!

More specifically, in terms of cognitive work, dealing with a new currency means having to perform conversion tasks from the old currency to the new one and vice versa.

This daily-life problem is the object of this research. Only one French work has (Lemaire, Lecacheur \& Barbey, 2001) investigated strategy use in currency conversion tasks. This research shows that French people used six strategies when they converted Euro into French Franc and four strategies when they converted French Franc into Euro; in each task, strategies appeared to differ in frequency and effectiveness and strategy choices were influenced by stimulus characteristics.

Following this research criteria and analysing the four strategic aspects proposed by Lemaire and Siegler (1995), we wanted to repeat the experiment in the Italian context and to continue it during the period of two years, investigating strategy use before and after the introduction of the Euro.

According to the framework proposed by Lemaire and Siegler (1995), the four strategic aspects that we studied were: strategy repertoire (variety of methods that people use to convert from one currency to another), strategy distribution (relative frequencies of 
each strategy), strategy execution (relative speed and accuracy) and strategy selection (how strategies are chosen).

Our hypotheses are that people use several strategies and each strategy is not used equally often. We predicted that some strategies are more efficient than others and that certain strategies are used more often on certain problems. Finally, we wanted to monitor the changes that could affect the strategies after one and a half years.

Method Participants

We recruited 82 students at the University of Bologna as participants: about half of them in Autumn 2001, immediately before the introduction of the Euro, and the other half in Spring 2003. Half of the participants were randomly assigned to the "Euro/Lira Conversion" condition and the other half to the "Lira/Euro Conversion" condition. All participants volunteered to take part in the experiment.

Stimuli

The material consisted of 20 digits for the "Euro/Lira Conversion" condition and 20 for the other condition. Digits were chosen following these criteria: a) tens (e.g. 20); b) non-tens (e.g. 23); c) tens plus one (e.g. 21); d) tens minus one (e.g. 19); e) digits with decimal point (e.g. 25.8) (Euro/Lira Conversion) or digits with hundreds (e.g. 25,800) (Lira/Euro Conversion).

Procedure

Participants were taken to a laboratory and asked to read instructions carefully on a computer screen. Their task was to convert the Euro digits into Lira or vice versa, one at a time. The experimental procedure followed that of Lemaire, Lecacheur and Barbey (2001). The experimental problems were randomly presented for each participant in the centre of the computer screen. Each trial began when the participant said that he/ she was ready to start and pressed the space bar on the keyboard. A number appeared on the screen, theparticipant converted it mentally (without any support), gave his/her verbal answer and pressed the space bar again. The timing of each trial began when the number appeared on the screen and ended when the participant pressed the space bar. The software used was E-Prime (Psychology Software Tools; Inc: http:// www.pstnet.com). After each response, in both conditions, participants were asked "which method did you use to convert the digit?" In each trial, the experimenter recorded the participants' response and verbal protocol. In the experiment conducted in Spring 2003, at the end of the trials, the experimenter asked the participants some questions about their everyday thinking: "in your everyday life, do you convert the Euro price into Lira or do you think directly in Euro?" Each participant was tested individually. Each session lasted between 20-30 minutes.

Results

Results for "Euro into Lira" and for "Lira into Euro" conversion tasks are presented separately. Unless otherwise noted, all statistics are significant to at least $p<.05$.

Euro into Lira Conversion, Autumn 2001Strategy repertoire

Three independent judges analysed the verbal protocols and classified the whole set of trials in 8 strategies. They agreed on $92 \%$ of trials and disagreements were resolved through discussion. On the basis of the same cut-off employed by Lemaire, Lecacheur and Barbey (2001), we performed our analysis considering only the strategies that were used in more than $5 \%$ of the whole trials. There were five such strategies that we considered: a) Multiply and Subtract; b) Anchor; c) Approximate; d) Transform; e) Other. "Multiply and Subtract" strategy consisted of multiplying the to-be-converted 
amount by 2,000 , and subtracting a certain amount decided by each participant. For $€ 9$, a participant might do the following: a) 9 x 2,000, b) 18,000 - 1,000, c) giving ITL 17,000 as an answer. "Anchor" strategy was used when participants referred to a value that is a point of reference in Euro. For $€ 9$, a participant might do: a) $9=9+1$, b) $10 \times 1,936=$ ITL 19,360, c) $€ 1=$ ITL 1,936, d) 19,360 - 1,936 = ITL 17,424. "Approximate" strategy consisted of neglecting the cents of the to-be-converted number, multiplying the resulting number by 2,000 and adding a certain amount decided by each participant. For $€ 9.40$, a participant might do the following: a) $9.40=9$, b) 9 × 2,000 = ITL 18,000, c) $18,000+1,000=$ ITL 19,000 as a result. "Transform" strategy consisted of changing the to-be-converted number into another, that is the nearest unit, before multiplying the transformed amount by 2,000 and subtracting a certain amount. For $€ 19$, a participant might do the following: a) transform 19 into 20, b) $€ 20$ is about 40,000 ITL, c) 40,000 $2,000=$ ITL 38,000. "Other" strategy included all those operations used by few people and not classified in those previous explained. For $€ 23$, a participant might do the following: a) $23 \times 2,000=\operatorname{ITL} 46,000$, b) $€ 1$ is about ITL 1,940, that is $2,000-60$, c) $60 \mathrm{x}$ $23=1,380$, d) $46,000-1,380=$ ITL 44,620.

Strategy distribution

The Cochran $Q$ Test showed a significant difference in the frequency of use of each of the 5 strategies, $Q(4)=282.36$. The comparisons among the strategies showed that the "Multiply and Subtract" strategy is the most used, see Fig. 1.

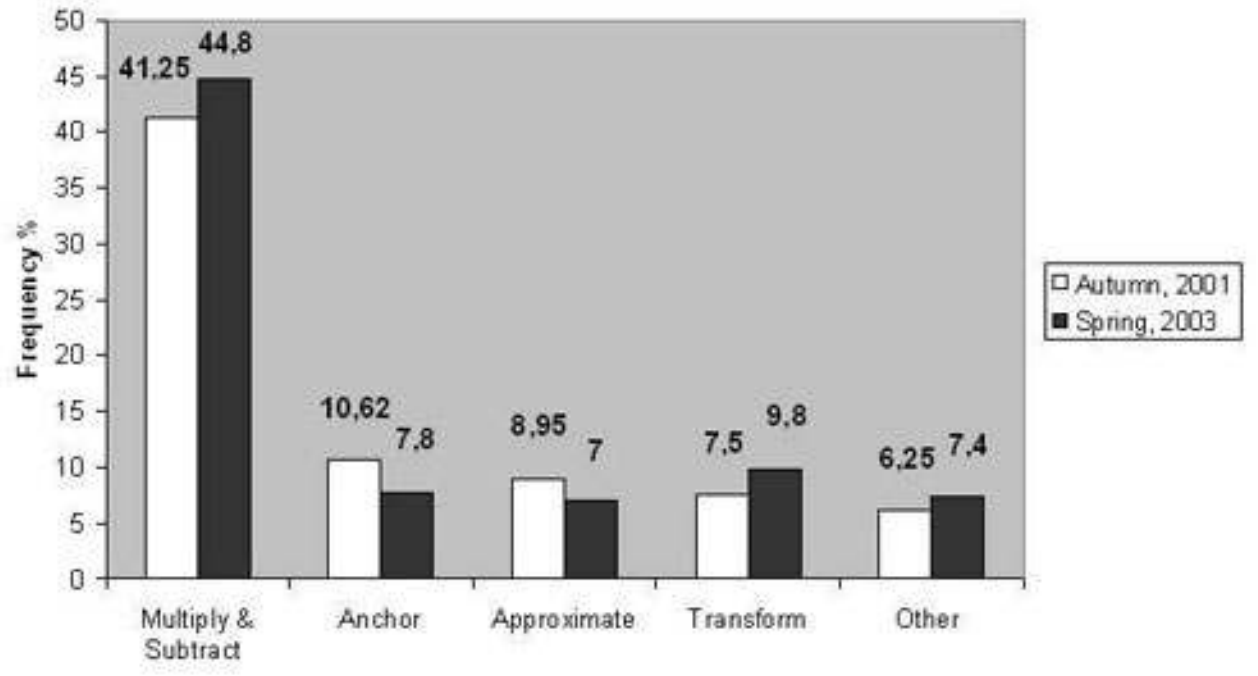

Figure 1. Euro into Lira Conversion: the frequency of strategy use in Autumn 2001 and Spring 2003.

Strategy and accuracy

We performed an analysis of variance (ANOVA) considering the 5 strategies as independent variables and the difference between the correct value and the response provided by the participants as a dependent variable. The results showed a significant difference, $F(4,353)=10.29$. Newman Keuls' post-hoc comparison showed that the "Anchor" strategy is the most accurate one. (See Table 1.)

Strategy and response time

We performed an ANOVA considering the 5 strategies as independent variables and the response time as a dependent variable. The results showed significant differences, $F(4$, $321)=17.41$. Newman Keuls' post-hoc comparison showed that the "Multiply and 
Subtract" strategy is quicker than "Anchor", "Approximate" and "Other". For the means see Table

Table 1. Euro into Lira Conversion: the table represents the mean difference and the mean response time related to each strategy in autumn 2001 and spring 2003.

\begin{tabular}{|l|l|l|l|l}
\cline { 2 - 5 } \multicolumn{1}{c|}{} & Autumn, 2001 & Spring, 2003 & Autumn, 2001 & Spring, 2003 \\
\hline Strategy & $\begin{array}{l}\text { Mean } \\
\text { Difference } \\
\text { (Lira) }\end{array}$ & $\begin{array}{l}\text { Mean } \\
\text { Difference } \\
\text { (Lira) }\end{array}$ & $\begin{array}{l}\text { Mean } \\
\text { Response Time } \\
\text { (sec) }\end{array}$ & $\begin{array}{l}\text { Mean Response } \\
\text { Time (sec.) }\end{array}$ \\
\hline Multiply \& Subtract & 1938.23 & 1805.33 & 11.75 & 8.84 \\
\hline Anchor & 785.24 & 665.41 & 21.27 & 10.18 \\
\hline Approximate & 22.48 .72 & 2096.26 & 17.88 & 12.45 \\
\hline Transform & 4539.42 & 2834.67 & 12.72 & 8.50 \\
\hline Other & 2202.57 & 1143.27 & 32.66 & 15.47 \\
\hline
\end{tabular}

Strategy selection

We performed a series of Cochran $Q$ tests to determine whether strategy use was related to stimulus characteristics so that participants showed a preference for some strategies over others for each type of digit. The results showed significant differences: "Multiply and Subtract" is the most frequently adopted strategy for every kind of digit (57-74\%), except for digits with a decimal point where the most frequently adopted strategy was "Approximate" (59\%). For the frequency see Tab. 2

Table 2. Euro into Lira Conversion: the table represent the frequency of use to each strategy related to each type of digits both for Autumn 2001 and Spring 2003.

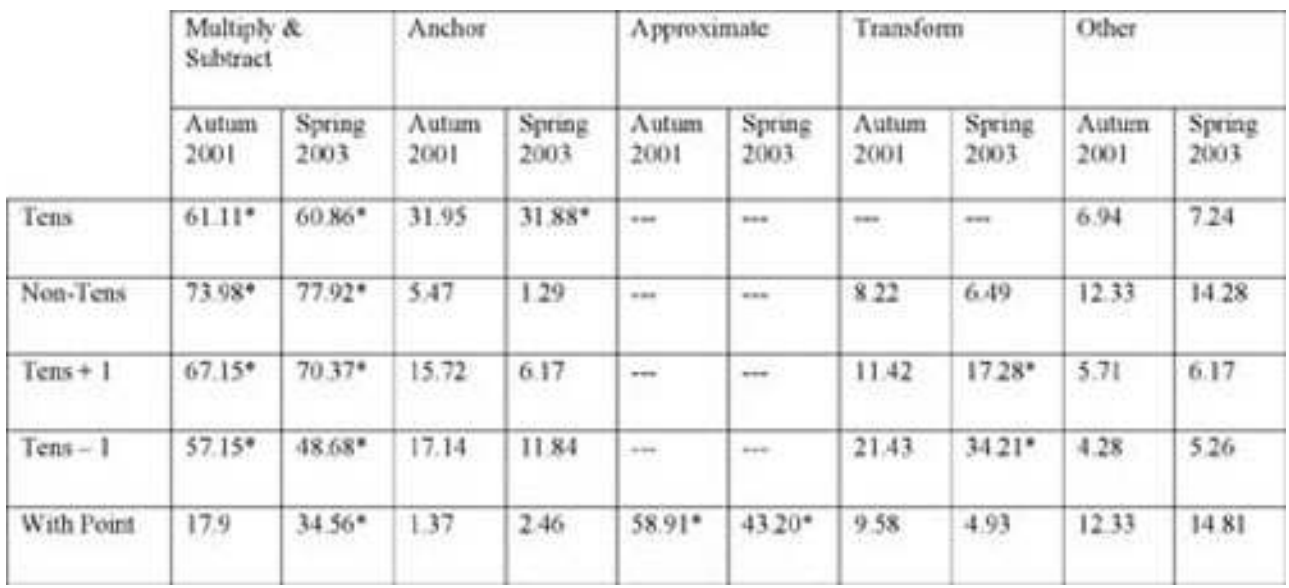

$\star p<0.05$

\section{Spring 2003Strategy repertoire}

Three independent judges analysed the verbal protocols and classified the whole set of trials in 8 strategies. They agreed on $94 \%$ of trials and disagreements were resolved through discussion. There were five strategies, which were used in more than $5 \%$ of the whole trials, that were: a) Multiply and Subtract; b) Anchor; c) Approximate; d) Transform; e) Other Strategy.

Strategy distribution. The Cochran $Q$ Test showed significant differences in the frequency of use of each of the 5 strategies, $Q(4)=354.17$. The comparisons among the strategies showed that "Multiply and Subtract" strategy is the most used, see Fig. 1.

Strategy and accuracy 
We performed an ANOVA considering the 5 strategies as independent variables and the difference between the correct value and the response provided by the participants as a dependent variable. The results showed significant differences, $F(4,379)=6.46$. Newman Keuls' post-hoc comparison showed that "Anchor" strategy is the most accurate one except for "Other" strategy (see Table 1).

Strategy and response time

We performed an ANOVA considering the 5 strategies as independent variables and the response time as a dependent variable. The results showed significant differences, $F(4$, $379)=11.9$. Newman Keuls' post-hoc comparison showed that the "Other" strategy is the slowest one. For the means see Table 1.

\section{Strategy selection}

We performed a series of Cochran $Q$ tests to determine whether strategy use was related to stimulus characteristics so that people showed a preference for some strategies over others for each kind of digit. The results showed significant differences. For each kind of digit there were 2 preferred strategies: "Multiply and Subtract" (61\%) and "Anchor" (32\%) for Tens; "Multiply and Subtract" and "Transform" for Tens plus one ( $70 \%$ and $17 \%$ respectively) and Tens minus one ( $49 \%$ and $34 \%$ respectively); "Multiply and Subtract" (35\%) and "Approximate" (43\%) for Digits with a decimal point. For Non-tens the most frequently adopted strategy was "Multiply and Subtract" (78\%). For frequencies see Table 2.

Lira into Euro Conversion, Autumn 2001Strategy repertoire

Three independent judges analysed the verbal protocols and classified the whole set of trials in 9 strategies. They agreed on $91 \%$ of trials and disagreements were resolved through discussion. There were six strategies that we considered: a) Divide; b) Divide and Add; c) Divide and Subtract; d) Transform; e) Approximate; f) Other. "Divide" strategy consisted of dividing the to-be-converted amount by 2,000. For ITL 9,000, a participant might do the following: a) 9,000 / 2,000, b) give $€ 4.5$ as an answer. "Divide and Add" strategy consisted of dividing the to-be-converted number by 2,000 and adding a certain amount decided by each participant. For ITL 9,000, a participant might do: a) $9,000 / 2,000=€ 4.5$, b) $4.5+1=€ 5.5$. "Divide and Subtract" strategy consisted of dividing the to-be-converted amount by 2,000 and subtracting a certain amount decided by each participant. For ITL 9,000, a participant might do: a) 9,000 / 2,000 =€ 4.5, b) $4.5-1=€ 3.5$. "Transform" strategy consisted of changing the to-be-converted number into another one, that is the nearest unit, before dividing the transformed amount by 2,000 and subtracting a certain amount. For ITL 19,000, a participant might do the following: a) transform 19,000 into 20,000, b) $20,000: 2,000=€ 10$, c) $10-0.5=€$ 9.5. "Approximate" strategy consisted of neglecting the hundreds of the to-beconverted number, dividing the resulting number by 2,000 and subtracting a certain amount decided by each participant. For ITL 9,600, a participant might do the following: a) $9,400=9,000$, b) $9,000: 2,000=€ 4.5$, c) $4.5-0.20=€ 4.3$ as a result. "Other" strategy included all those operations used by few people and not classified in those previous explained. For ITL 24,000, a participant might do the following: a) 24,000 / $2,000=€ 12, b) € 1$ is about ITL 1,940 , which is $2,000-60$, c) ITL 60 is about $€ 0.03$ d) 0.03 $\mathrm{x} 12=€ 0.36, \mathrm{~d}) 12+0.36=€ 12.36$.

Strategy distribution

The Cochran $Q$ Test showed a significant difference in the frequency of use of each of the 6 strategies, $Q(5)=76.29$. The comparisons among the strategies showed that the 
"Divide and Add" is the most frequently adopted strategy of all, except for "Transform" which, anyway, did not significantly differ from all the other strategies. (See Fig. 2.)

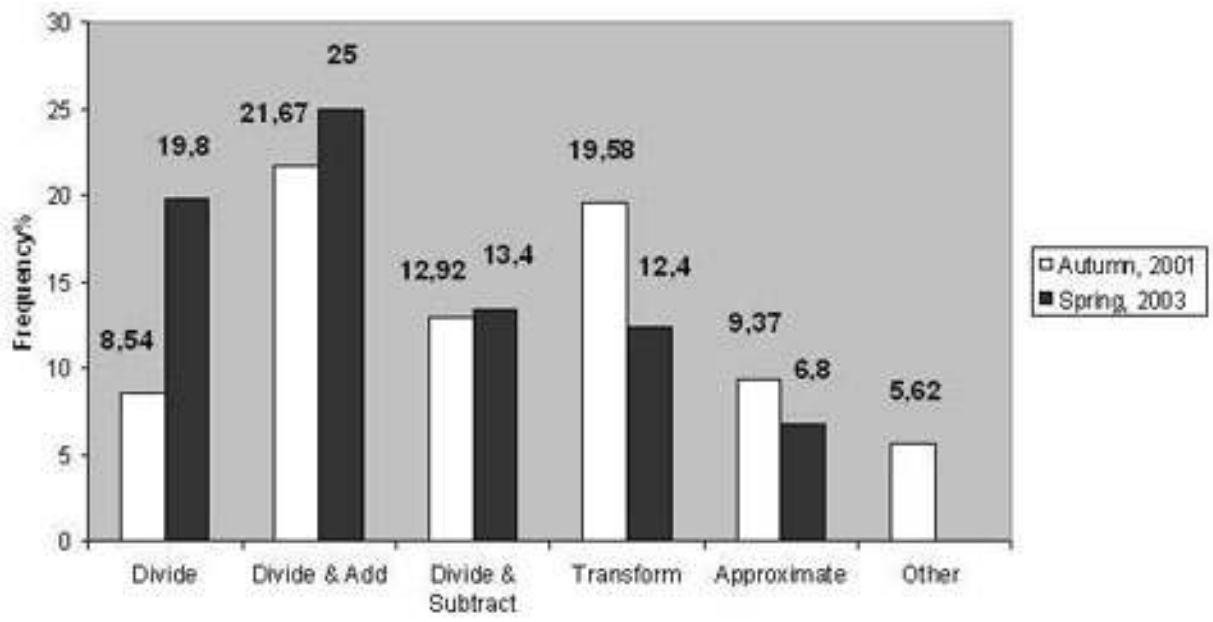

Figure 2. Lira into Euro Conversion: the frequency of strategy use in Autumn 2001 and Spring 2003.

Strategy and accuracy

We performed an ANOVA considering the 6 strategies as independent variables and the difference between the correct value and the response provided by the participants as a dependent variable. The results did not show any significant differences, $F(5,367)=.84$, $p=.52$. The means are represented in Table 3 .

Table 3. Lira into Euro Conversion: the table represents the mean difference and the mean response time related to each strategy in autumn 2001 and spring 2003.

\begin{tabular}{|l|l|l|l|l|}
\cline { 2 - 5 } \multicolumn{1}{c|}{} & Autumn, 2001 & Spring, 2003 & Autumn, 2001 & Spring, 2003 \\
\hline Strategy & $\begin{array}{l}\text { Mean } \\
\text { Difference } \\
\text { (Euro) }\end{array}$ & $\begin{array}{l}\text { Mean } \\
\text { Difference } \\
\text { (Euro) }\end{array}$ & $\begin{array}{l}\text { Mean } \\
\text { Response } \\
\text { Time (sec.) }\end{array}$ & $\begin{array}{l}\text { Mean } \\
\text { Response } \\
\text { Time (sec.) }\end{array}$ \\
\hline Divide & .78 & .93 & 7.13 & 7.71 \\
\hline Divide \& Add & 1.19 & 78 & 9.95 & 8.64 \\
\hline Divide \& Subtract & 1.51 & 1.42 & 9.40 & 7.68 \\
\hline Transform & 1.13 & .99 & 15.10 & 7.62 \\
\hline Approximate & .60 & -74 & 8.95 & 13.05 \\
\hline Other & 1.20 & $\ldots$ & 27.51 & $\ldots$ \\
\hline
\end{tabular}

Strategy and response time

We performed an ANOVA considering the 6 strategies as independent variables and the response time as a dependent variable. The results showed significant differences, $F(5$, $367)=20.88$. Newman Keuls' post-hoc comparison showed that "Other" is the slowest strategy followed by “Transform”. For the means see Table 3.

Strategy selection

We performed a series of Cochran $Q$ tests to determine whether strategy use was related to stimulus characteristics so that participants showed a preference for some strategies over others for each type of digit. The results showed significant differences.

The most frequently adopted strategies were: "Divide and Add" (44\%) for Non-tens; "Divide and Subtract" (33\%) and "Transform" (38\%) for Tens plus one; "Transform" (61\%) for Tens minus one; "Approximate" (59\%) for Digits with hundreds. For Tens, 
however, there was no one strategy which was used more frequently than others. For frequencies see Table 4.

Table 4. Lira into Euro Conversion: the table represent the frequency of use to each strategy related to each type of digits both for Autumn 2001 and Spring 2003.

\begin{tabular}{|c|c|c|c|c|c|c|c|c|c|c|c|}
\hline \multicolumn{2}{|c|}{ Diside } & \multicolumn{2}{|c|}{ Divide and Add } & \multicolumn{2}{|c|}{$\begin{array}{l}\text { Divide and } \\
\text { Subtract }\end{array}$} & \multicolumn{2}{|c|}{ Apreusimate } & \multicolumn{2}{|c|}{ Trausform } & \multicolumn{2}{|l|}{ Odact } \\
\hline $\begin{array}{l}\text { Metam } \\
\text { 200t }\end{array}$ & $\begin{array}{l}5 \text { Frive } \\
2003\end{array}$ & $\begin{array}{l}\text { Aviliem? } \\
\text { oot }\end{array}$ & $\begin{array}{l}\text { Sprive } \\
\text { 2cos }\end{array}$ & $\begin{array}{l}\text { A vinit } \\
2001\end{array}$ & $\begin{array}{l}\text { Syniat } \\
\text { sooy }\end{array}$ & $\begin{array}{l}\text { Aisum } \\
201\end{array}$ & $\begin{array}{l}\text { Spriag } \\
2003\end{array}$ & $\begin{array}{l}\text { Antum } \\
2001\end{array}$ & $\begin{array}{l}\text { Spring } \\
\text { ano3. }\end{array}$ & $\begin{array}{l}\text { Sutiam } \\
\text { 3001 }\end{array}$ & $\begin{array}{l}\text { Sorias } \\
2003\end{array}$ \\
\hline 30 & $48.68^{\circ}$ & 4125 & $3684^{\circ}$ & 33.75 & 14.47 & - & $\ldots$ & - & $m$ & 5* & $m$ \\
\hline 12.12 & 33.76 & $43.93^{\circ}$ & 4155 & 2424 & 18.18 & - & - & 12.12 & $6.45^{\circ}$ & 757 & - \\
\hline 769 & 20 & 1794 & 1240 & $3333^{\circ}$ & 20 & - & $=$ & $18+6^{\circ}$ & 27.40 & 256 & - \\
\hline 5.90 & 17.72 & 1736 & 2011 & 9.45 & 16.45 & - & $\cdots$ & $00 \times 1^{\circ}$ & $3797^{\circ}$ & 6.75 & $\omega$ \\
\hline 526 & 8 & 1052 & 2266 & 263 & 1733 & $59121^{\circ}$ & $4533^{\circ}$ & 921 & 16 & 13.15 & $\cdots$ \\
\hline
\end{tabular}

* $p<0.05$

Spring 2003Strategy repertoire

Three independent judges analysed the verbal protocols and classified the whole set of trials in 9 strategies. They agreed on $93 \%$ of trials and disagreements were resolved through discussion. There were five strategies that we considered: a) Divide; b) Divide and Add; c) Divide and Subtract; d) Transform; e) Approximate. Compared to the previous experiment, the "Other" strategy disappears.

Strategy distribution

The Cochran Q Test showed significant differences in the frequency of use of each of the 5 strategies, $Q(4)=64.1$. The comparisons among the strategies showed that the most often used were "Divide" and "Divide and Add" strategies, see Fig. 2.

Strategy and accuracy

We performed an ANOVA considering the 5 strategies as independent variables and the difference between the correct value and the response provided by the participants as a dependent variable. The results showed significant differences, $F(4,382)=4.41$. Newman Keuls' post-hoc comparison showed that there was no one strategy which was more accurate than others, but the least accurate was "Divide and Subtract". The means are represented in Table 3.

Strategy and response time

We performed an ANOVA considering the 5 strategies as independent variables and the response time as a dependent variable. The results showed significant differences, $\mathrm{F}(4$, $382)=7.25$. Newman Keuls post-hoc comparison showed that "Approximate" is the slowest strategy. The means are represented in Table 3.

Strategy selection

We performed a series of Cochran $Q$ tests to determine whether strategy use was related to stimulus characteristics so that people showed a preference for some strategy over others for each kind of digit. The results showed significant differences: the most frequently adopted strategies for Tens were "Divide" (49\%) and "Divide and Add" (37\%); "Transform" (38\%) for Tens minus one; "Approximate" (45\%) for Digits with hundreds. For Tens plus one and Non-tens, there was not a preferred strategy. For frequencies see Table 4.

Comparison between Autumn 2001 and Spring 2003Accuracy

We performed a two-ways ANOVA considering the different periods in which the experiments were conducted and the conversion strategies as independent variables. The results did not show any significant differences, neither from Euro into Lira ( $F(4$, $732)=.60, p=.66)$ nor from Lira into Euro $(\mathrm{F}(5,755)=.29, p=.91)$ Conversion Condition. 


\section{Response Time}

We performed a two-ways ANOVA considering the different periods in which the experiments were conducted and the conversion strategies as independent variable. Euro into Lira Conversion results showed significant differences "period x strategy", $F(4,732)=3.34$. Newman Keuls' post-hoc comparison showed that "Anchor" and "Other" strategies are quicker in 2003 than in 2001. For comparisons see Table 1. Lira into Euro Conversion results did not show any significant result $(F(4,723)=.57, p=.68)$. For comparisons, see Table 3.

Number of strategy

We analyzed the strategy distribution across participants for both conversion tasks. As can be seen in Table 5, in Euro to Lira conversion after one year and half the number of subjects that use just one or two strategies is increased, while in Lira to Euro conversion the number of subjects that use more than three strategies is greater.

Table 5. Number of strategy used distribution: the table shows the percentage of subjects that used a certain number of strategies (from 1 to 5 ) to convert currency both for spring and autumn sessions.

\begin{tabular}{l|l|l|l|l|}
\hline \multirow{2}{*}{\begin{tabular}{l} 
Number \\
\multirow{2}{*}{$\begin{array}{l}\text { of } \\
\text { Strategies }\end{array}$}
\end{tabular}} & \begin{tabular}{l} 
Euro to Lira \\
\cline { 2 - 5 } \\
Autumn
\end{tabular} & Spring 2003 & $\begin{array}{l}\text { Lutumn } \\
2001\end{array}$ & Spring 2003 \\
\hline 1 & $0 \%$ & $10 \%$ & $5 \%$ & $0 \%$ \\
\hline 2 & $10 \%$ & $24 \%$ & $5 \%$ & $5 \%$ \\
\hline 3 & $45 \%$ & $19 \%$ & $45 \%$ & $10 \%$ \\
\hline 4 & $30 \%$ & $33 \%$ & $20 \%$ & $57 \%$ \\
\hline 5 & $15 \%$ & $14 \%$ & $25 \%$ & $28 \%$ \\
\hline
\end{tabular}

Final Questionnaire

Cochran $\mathrm{Q}$ test showed significant differences among participants' responses $(\mathrm{Q}(2)=$ 8.14): $52.4 \%$ answer that they still think in Lira, $16.6 \%$ answer that they think in Euro and, finally, 31\% answer that they think both in Lira and Euro depending on the type of digits, that is, when they have to manage with small prices they think directly in Euro, while for more expensive goods they still prefer to convert the amount into Lira.

Conclusions

The present research has been conducted to monitor a phenomenon which has been defined as a "great natural experiment" (Legrenzi, 1998) and whose participants have been all the citizens of the European Union States: the introduction of a new currency.

During the period of two years we studied the way through which, spontaneously, people try to solve the problem linked to this change, analysing the conversion strategies from Italian Lira to Euro and vice versa.

First of all, we wanted to know how many strategies people used, if each strategy was used equally often and if these strategies would last for a long time. We showed that people accomplish currency conversion tasks by using at least 5 different strategies to convert the two currencies and that the same strategies have lasted during the period of one and a half years without changing.

From a human cognition point of view, these results suggest that, as noted by Lemaire and Lecacheur (2001), people know and use multiple strategies to accomplish most 
cognitive tasks and that such tasks have similar characteristics to other high-level problem solving tasks (Lemaire, Lecacheur \& Barbey, 2001).

From a psychological point of view our findings showed that, after one year of Euro, Italian people still convert the prices from Euro into Lira and vice versa and find it difficult to think in the new currency with immediacy. The social implications of these results are that people, when interacting in economic exchanges, think in terms of a medium that no longer exists.

In fact, $52.4 \%$ of the participants said that they still have to convert the amount either if they have to buy a product and see the Euro price, converting it into Lira, or if they have to think about an amount they want to spend, first in Lira and then converted into Euro.

Only $16.6 \%$ of the participants declare that they think directly in Euro and that they find the task difficult at the date of experiment because now it is unusual to make conversions between Euro and Lira.

The last $31 \%$ of the participants seem to be in a handover phase: for big numbers they still use the conversion between currencies, while only for smaller numbers and for the prices of commonly-used products, like for coffee or newspapers, do they succeed in thinking immediately in Euro. Anyway, this means that in our everyday life the old currency is still an important term of comparison, probably, as Dehaene and Marques (2002) argued, because the creation of the "mental map" of prices in Euro needs a long time and much practice with the new currency. That is probably the reason why our participants feel comfortable only with prices of commonly-used products, which have repeated exposure once or twice a day.

This result is also in accordance with Logan's (1988) theory on the acquisition of automaticity: automatization involves a strategic shift from reliance on an initial algorithm that is sufficient to perform the task (i.e., the mental calculation of the price in euro from the estimates price in the former national currency) to reliance on memory-based solutions (i.e., the prices in euro). A recent work (Marques \& Dehane, 2004) on numerical intuition for prices reached similar results; the authors studied price estimations in euros either in Portugal or in Austria, from November 2001 to June 2002, and show that they have not yet reached a level of accuracy comparable with estimations in the former national currency. Moreover it seems that people made an adaptation to the euro by first relearning the prices for the items that they frequently bought and only later for the items that they rarely bought.

Following these principles it seems correct to think that price intuition in the novel currency can be accounted by a relearning hypothesis which sustain that mapping can only develop with a slow process of association that requires exposure to many product-price pairs. Reliance on the calculation algorithm should continue as long as this new mapping is being established, and direct retrieval of the prices in euro is not yet possible or simply takes longer than computing them from the estimated price in the former national currencies.

This research shows not only that we use strategies of conversion between the two currencies, but also that these strategies have not changed during the period of one and a half years. This means that, even though people had the opportunity to practice with this kind of mental operation, they did not succeed in specialising, that is, preferring just one of the strategies or finding new ones. 
In any case, after one and a half years, there have been some changes in the use of these strategies.

First of all, concerning the distribution of the strategies, for the conversion from Lira into Euro, the rounded figure strategy, divide by 2000 , is getting to be the most often used, probably because it is the most convenient.

In the meanwhile, the strategy that subtracts an amount after dividing the number, instead of adding it, which is conceptually wrong, is now less frequently adopted. Except for these two differences, the strategies remain the same after one and a half years and the most often used is always the one that subtracts or adds an amount, decided by the participant, after having multiplied or divided the number by 2000 .

Even if the strategies are the same after one and a half years, now their distribution, depending on the digit to be converted, has changed.

In fact, when converting Euro into Lira, one and a half years ago people preferred the same strategy for every kind of digit, while now there is more variability; the strategies are chosen depending on the digit to be converted. The strategy that subtracts an amount after having multiplied the number is used together with another strategy, different for each digit, which is more functional for each problem to solve: for example, for tens, people also use the strategy that anchors the number to a point of reference in Lira.

One of the reasons for this result could be that, at the end of 2001, people did not have knowledge and familiarity with the new currency, so they could not handle it in an easy and flexible way, while, after one and a half years of practice, people feel more comfortable and can try to specialise, finding the best strategy for each problem.

On the other hand, when converting Lira into Euro, we can see the opposite phenomenon: in the first experiment people had more confidence with the Lira, and so could prefer a different strategy for each digit; after one and a half years without Lira, they lost their specialisation and so they utilise the strategies without depending on the number they have to convert.

These mirror changes, in our opinion, can account for the creation of the new mental mapping of prices in Euro (Dehaene and Marques, 2002).

Moreover, the number of strategies used by each participant is different between the two experiments: after one year and half every single person use a lower number of strategies to convert Euro to Lira, while there's a mirror result in the conversion to Lira to Euro: this is another datum that can account for the specialization of the use of strategies and the familiarization with the new currency.

In terms of accuracy, there are no significant differences between the two experiments.

For Euro into Lira conversion, the most accurate strategy is still the one which refers to anchor values in Lira, but now it is also faster than one and a half years ago. This result is consistent with the coming apart of the price memory from the old currency and the consequent fixing on a new system (Legrenzi, 2001): the anchor is now automatic, and so faster.

For Lira into Euro conversion there is no difference in accuracy between the strategies, as there was one and a half years ago, except for the wrong strategy (i.e. "Divide and subtract"), which is, obviously, the worst. This strategy is not a valid one and is, of course, inefficient, but it is still used in $13 \%$ of cases. 
An interesting result is the one concerning the speed of the strategies: people now make faster conversions between currencies. This finding is another datum in support of the relearning hypothesis discussed above (Marques \& Dehane, 2004) and it reflects, in our opinion, the continuing practice of everyday shopping that contribute to make the task more automatic and, so, faster.

In conclusion, after one and a half years, people are getting more familiar with the Euro and can take the opportunity to make a more strategic use of the conversion strategies: the process is becoming automatic and, consequently, faster. This year of practice, on the other hand, is not sufficient to modify the strategies which, once determined, are the only ones to be used, resisting change even when it could be functional for a better solution of the problem.

Furthermore, these results can be viewed in terms of cognitive economy: one characteristic of our cognitive system is the adaptive skill towards change; this can be usually accomplished employing some kind of heuristics which can facilitate the problem-solving. Our work shows, in this case, that the cognitive system has not yet developed a strategic procedure to improve accuracy of conversion between currencies, but its adapting ability is only reflected by the speed of conversion.

\section{BIBLIOGRAPHY}

Bini Smaghi, L. (2001). L'euro. Con la nuova moneta in tasca. Bologna, Italy: Il Mulino.

Dehaene, S., \& Marques, J. F. (2002) Cognitive euroscience: Scalar variability in price estimation and the cognitive consequences of switching to the euro. The Quarterly Journal of Experimental Psychology, 55 A, 705-731.

Everdingen, Y. M. van, \& Raaij W. F. van (1998). The Dutch people and the euro: a structural equations analysis relating national identity and economic expectations to attitude towards the euro. Journal of Economic Psychology, 19, 721-740.

Gamble, A., Gärling, T., Charlton, J., \& Ranyard, R. (2002). Euro illusion: Psychological insights into price evaluations with a unitary currency. European Psychologist, 7 (4), 302-311.

Kokkinaki, F. (1998). Attitudes towards European Monetary Union in Greece: antecedents, strength and consequences. Journal of Economic Psychology, 19, 775-796.

Legrenzi, P. (1998). L'euro e la vita quotidiana. Il Mulino, 377, 457-465.

Legrenzi, P. (2001). Psicologia cognitiva applicata all'euro. In P. Legrenzi, Psicologia cognitiva applicata. Pensare e comunicare (pp. 187-210). Roma, Italy: Laterza.

Legrenzi, P., \& Salmaso, P. (1999). Euro, cognizione, marketing. Micro e Macro Marketing, 8, 265-279.

Lemaire, P., \& Siegler, R. S. (1995). Four aspects of strategic change: Contributions to children's learning of multiplication. Journal of Experimental Psychology: General, 124, 83-97. 
Lemaire, P., \& Lecacheur, M. (2001). Older and younger adults' strategy use and execution in currency conversion tasks: Insights from French Franc to Euro and Euro to French Franc conversions. Journal of Experimental Psychology: Applied, 3, 195-206.

Lemaire, P., Lecacheur, M., \& Barbey M. F. (2001). Strategy Use in Currency Conversion Tasks: The examples of Euros to French Franc and French Franc to Euro Conversions. Current Psychology Letters, 4, 39-50.

Logan, G. D. (1988). Toward an instance theory of automatization. Psychological Review, 95, 492-527.

Marques, J. F. (1999). Changing EUROpe: the euro as a new participant for psychological research in numerical cognition. European Psychologist, 4, 152-156.

Marques, J. F., \& Dehane, S. (2004). Developing intuition for prices in euros. Rescaling or relearning prices? Journal of Experimental Psychology: Applied, 10, 148-155.

Meier, K., \& Kirchler, E. (1998). Social representations of the Euro in Austria. Journal of Economic Psychology, 19, 755-774.

Müller-Peters, A. (1998). The significance of national pride and national identity to the attitude toward he single European currency: a Europe-wide comparison. Journal of Economic Psychology, 19, 701-719.

Mussweiler, T., \& Englich, B. (2003). Adapting to the Euro: Evidence from bias reduction. Journal of Economic Psychology, 24, 285-292.

Pepermans, R., \& Verleye G. (1998). A unified Europe? How euro-attitudes relate to psychological differences between countries. Journal of Economic Psychology, 19, 681-699.

Raimondi, M. (1998). L'euro e il suo impatto sul marketing. Micro e Macro Marketing, 1, 89-110.

Routh, D. A., \& Burgoyne, C. B. (1998). Being in two minds about a single currency: a UK perspective on the euro. Journal of Economic Psychology, 19, 741-754.

\section{ABSTRACTS}

This study reports an investigation of strategy use in the conversion of Euro into Lira and Lira into Euro. We demonstrate that in Autumn 2001 - immediately before the introduction of the Euro - Italian people used multiple strategies to accomplish the conversion tasks. In each task, strategies showed differences in frequency, accuracy and speed. After one and a half years, this pattern shows interesting changes: the use of the strategies is different and people are quicker in the conversion task, which is becoming automatic. Our findings show that, even in Spring 2003, Italian people still convert prices from Euro into Lira and vice versa and find it difficult to think in the new currency with immediacy.

L'objet de cette recherche est l'étude des stratégies de conversion des Euro en Lire et des Lires en Euro. Nous montrons qu'en automne 2001 - juste avant l'introduction de l'Euro - les Italiens utilisaient un grand nombre de stratégies différentes pour accomplir la tâche de conversion. Ces stratégies différaient quant à leur fréquence, leur exactitude et leur rapidité. Une année et demie après, on observe des changements intéressants: les stratégies utilisées sont différentes et les gens sont plus rapides dans les tâches de conversion, celle-ci devenant automatique. Mais ils montrent aussi que les Italiens continuent toujours au printemps 2003 à convertir les prix des Euro en Lires et vice-versa et qu'ils trouvent difficile de penser rapidement dans la nouvelle monnaie. 
INDEX

Mots-clés: Euro

Keywords: Conversion Between-Currency, Strategy Use, Numerical Cognition, Currency

\section{AUTHORS}

\section{ELEONORA STRAZZARI}

Department of Psychology, University of Bologna

V.le Berti Pichat, 5

40127 Bologna, Italy

Phone number: +39 051 2091342, Fax: +39 051243086

\section{RAFFAELLA NORI}

Department of Psychology, University of Bologna

\section{LUCA BENSI}

Department of Psychology, University of Bologna

\section{FIORELLA GIUSBERTI}

Department of Psychology, University of Bologna fiorella.giusberti@unibo.it 